\title{
Intake of cardiovascular drugs promote severity of anaphylaxis
}

\author{
Sabine Dölle ${ }^{1 *}$, Günter Edenharter ${ }^{2}$, Franziska Ruëff ${ }^{3}$, Margitta Worm ${ }^{1}$ \\ From Food Allergy and Anaphylaxis Meeting 2014 \\ Dublin, Ireland. 9-11 October 2014
}

\section{Background}

Cofactors may contribute to the elicitation and severity of anaphylaxis in about $30 \%$ of anaphylactic reactions. Clinical data from registries can support the identification and risk impact of such cofactors. Besides exercise or alcohol, drugs are known to facilitate anaphylactic reactions. The facilitating effect of cardiovascular drugs to hymenoptera stings is controversially discussed; data on the association of cardiovascular drugs and anaphylaxis due to other elicitors are not available.

\section{Objective}

To assess whether cardiovascular drugs like beta-blockers and angiotensin-converting enzyme (ACE)-inhibitors alter the risk for severe anaphylaxis.

\section{Methods}

Data from the German-speaking anaphylaxis registry were collected from January 2006 to March 2013 and analysed. The impact of beta-blockers and/or ACE-inhibitors on the severity of anaphylaxis was calculated by using a logistic regression model.

\section{Results}

The statistical analysis showed an elevated risk of severe anaphylaxis (grade I/II $n=2355$ versus grade III/IV $\mathrm{n}=1686$ ) in patients with beta-blocker or ACE-inhibitor treatment (odds ratios (OR): monotherapy with ACE-inhibitor 1.37 [0.94-1.98], monotherapy with beta-blocker 1.36 [1.09-1.72], $p$-value $=0.008$ to patient without contribution of cofactors), which was more pronounced when both drugs were taken (OR: combined therapy with ACE-inhibitor/beta-blocker 1.70 [1.28-2.26], $p$-value <0.001). These findings were more prominent if grade I-III versus very

${ }^{1}$ Department of Dermatology and Allergology, Charité-University Medicine Berlin, Allergy Centre Charité, Berlin, Germany

Full list of author information is available at the end of the article severe reactions (grade IV; OR: drug combination 2.44 [1.31-4.53], p-value $=0.005$ ) were calculated. Adjustment of sex and age reduced the OR, however, the results still indicate clinical relevant effect sizes (OR: drug combination 2.07 [1.04-4.12]). The effects were independent of the type of elicitor (food, drug, insect stings and others) of the anaphylactic reaction.

\section{Conclusion}

Our data show that patients treated with beta-blockers and/or ACE-inhibitors have an increased risk to develop more severe anaphylactic symptoms. Interestingly, both drugs seem to synergistically aggravate the anaphylaxis.

\section{Authors' details \\ ${ }^{1}$ Department of Dermatology and Allergology, Charité-University Medicine Berlin, Allergy Centre Charité, Berlin, Germany. 'Edenharter Research, Berlin, Germany. ${ }^{3}$ Department of Dermatology and Allergology, Ludwig-Maximilian University, Munich, Germany.}

Published: 30 March 2015

doi:10.1186/2045-7022-5-S3-P4

Cite this article as: Dölle et al:: Intake of cardiovascular drugs promote severity of anaphylaxis. Clinical and Translational Allergy 2015 5(Suppl 3):P4.

Submit your next manuscript to BioMed Central and take full advantage of:

- Convenient online submission

- Thorough peer review

- No space constraints or color figure charges

- Immediate publication on acceptance

- Inclusion in PubMed, CAS, Scopus and Google Scholar

- Research which is freely available for redistribution 